\title{
NAHUI OLIN: \\ UNA MIRADA LÚCIDA ${ }^{1}$
}

\author{
Rocío Luque ${ }^{2}$
}

\begin{abstract}
Nahui Olin: Una mirada lúcida
Resumen: Nahui Olin, una de las artistas más versátiles y más bellas del México de los años veinte, tras un periodo fecundo de producción poética y pictórica, sufrió una progresiva etapa de marginación, en la que acabó por ser tildada simplemente como "loca". En este estudio, a través del análisis de la palabra "locura" en el sentido filosófico del término, observamos cómo Nahui compartió en efecto todos los aspectos de este fenómeno, mostrando en realidad, sobre todo en Óptica cerebral, una mirada acerca de la concepción de sí misma, de la condición femenina y de la creación intelectual, sumamente lúcida.
\end{abstract}

Palabras clave: Nahui Olin, Óptica cerebral, locura, poesía, mujer.

Nahui Olin: A lucid gaze

Abstract: Nahui Olin, one of the most versatile and beautiful artists of Mexico's twenties, after a fruitful period of poetic and pictorial production, suffered a progressive stage of marginalization, in which she will be branded simply as "crazy". In this study, through the analysis of the word "madness" in the philosophical sense, we see how Nahui indeed shared all aspects of this phenomenon, showing reality, especially in Óptica cerebral, a gaze about the conception of oneself, the status of women and intellectual creation, extremely lucid.

Key words: Nahui Olin, Óptica cerebral, madness, poetry, woman.

\section{Nahui Olin: varia locura}

Según Platón, la locura buena, es decir, la que no es una enfermedad o una perdición, se ha concebido de dos maneras distintas: como inspiración o don divino; o como amor hacia la vida y la tendencia a vivirla de manera simple. El primer significado es el que le atribuyó Platón en el Fedro, afirmando que los mayores bienes fueron dones divinos recibidos por medio de una locura. Esta se manifiesta de cuatro maneras: la locura profética, la locura purificatoria, la locura poética y la locura amorosa. Esta última se conecta con el segundo significado de la palabra, en base al cual la locura es el amor hacia

${ }^{1}$ Fecha de recepción: 1/12/2015

Fecha de aceptación: 19/12/2015.

${ }^{2}$ Profesora Contratada, Dipartimento di Lingue e letterature, comunicazione, formazione e società, Università degli Studi di Udine, Udine, Italia; $\bowtie$ rocio.luque @uniud.it. 
la vida en su simplicidad, de manera contrapuesta a la sabiduría artificiosa y a la ciencia de quien sabe hacer todo menos vivir y amar (Abbagnano 2011: 798) ${ }^{3}$.

Nahui Olin ${ }^{4}$ (1893-1978), una de las artistas más versátiles y una de las mujeres más bellas de México, que vivió los mejores años de este país latinoamericano, los veinte $^{5}$, posee todos los aspectos de la locura en el sentido filosófico del término. Y no es una casualidad si Elena Poniatowska, en su colección de ensayos Las siete cabritas (2006), la coloca junto con otras grandes mujeres que comparten con ella el signo que acarrea la locución española “estar como una cabra”: Frida Kahlo, Pita Amor, Nahui Olin, María Izquierdo, Elena Garro, Rosario Castellanos y Nellie Campobello.

Si la locura profética se concibe como la capacidad divinatoria, Nahui la manifestó desde temprana edad. Su maestra del Colegio Francés de San Cosme, Marie Louise Crescence, una monja que conservaba Las flores del mal de Baudelaire en su devocionario y era conocedora de Voltaire, Lamartine y Rousseau, afirmó: "Esta niña es extraordinaria. Todo lo comprende, todo lo adivina, su intuición es pasmosa. A los diez años habló el francés como yo que soy francesa, y escribía las cosas más extrañas del mundo, algunas completamente fuera de nuestra disciplina religiosa" (Poniatowska 2006: 63). Nahui, de hecho, desde su pupitre escolar escribió unos textos sorprendentes para su edad, que fueron publicados bajo el título $A$ dix ans sur mon pupitre ${ }^{6}$ (1924) por la editorial Cultura. En ellos manifiesta una extraordinaria precocidad intelectual y una sed

\footnotetext{
${ }^{3}$ El Elogio de la locura (1511) de Erasmo de Rotterdam es la mayor defensa de este segundo significado del término.

${ }^{4}$ María del Carmen Mondragón Valseca, conocida como Nahui Olin, fue una mujer y una artista que transgredió los valores opresivos de la sociedad mexicana de las primeras décadas del siglo XX. Hija del general Manuel Mondragón y de Mercedes Valesco, una mujer sensible que inculcó en sus hijos el amor a la pintura y a la música, nace el 8 de julio de 1893 en Tacubaya, Ciudad de México. Su infancia y su juventud transcurrieron entre México, París y San Sebastián, a causa de los acontecimientos políticos que involucran al padre, educándose en los mejores colegios. Desde muy pequeña, Carmen se rebeló en contra de los preceptos y la disciplina tradicionales impuestos por su madre (Rosas Lopátegui 2010: 87).

${ }^{5}$ Son los años en los que el escritor y político José Vasconcelos, junto con todos los artistas de la época, concibe un país que se levanta de las cenizas de la Revolución Mexicana gracias al acto de la creación y a la convicción de que el arte es de todos.

${ }^{6}$ Esta obra, así como Câlinement je suis dedans, fue traducida por mí al español bajo el título A los diez. años en mi pupitre y publicada, de manera parcial en las ediciones de Patricia Rosas Lopátegui Feminine Transgression. Transgresión Femenina (2010) y Óyeme con los ojos. De Sor Juana al siglo XXI. 21 Escritoras mexicanas revolucionarias, vol. 1, (2010); y de manera íntegra en Nahui Olin. Sin principio ni fin. Vida, obra y varia invención (2011).
} 
insaciable de conocimiento, plantea sus deseos de independencia, libertad y anhelos creadores, y pone en tela de juicio la opresión del ser femenino en la sociedad patriarcal ${ }^{7}$.

La locura purificatoria es la que permite alejarse del mal por medio de una iniciación, que en Nahui pasa por los ojos, puesto que son estos órganos los que le permiten iniciarse al mundo y los que permiten que los demás se inicien a ella. Sus ojos, de un verde que se intuye hasta en las fotografías en blanco y negro, son de un erotismo brutal, casi violento, y son capaces de capturar la atención de cualquiera que se cruce con su mirada:

¿Qué tienen esos ojos? La atrapan. Adriana vuelve a mirar. Los ojos se apoderan de ella, diabólicos, igual que años atrás le ocurrió a Tomás Zurián y antes todavía al Dr. Atl, a Diego Rivera, a Carlos Chávez, a Edward Weston, a Raoul Fournier, a Antonio Garduño, a Matías Santoyo, a Eugenio Agacino, el capitán de navío, y ¿por qué no?, a Manuel Rodríguez Lozano. Entre todos, sin embargo, el general Manuel Mondragón fue el primero; a él, antes que a nadie, sedujo el resplandor de ese par de soles, de incendios, de infiernos. Esa niña impredecible, de bucles rubios, berrinches y pataletas, esa criatura suya, encarnación de Luzbel, el ángel caído.

¿Qué tienen esos ojos? En medio del pasmo, Adriana Malvido tarda en encontrar la respuesta. Un hecho resulta ya innegable: Adriana es víctima de Nahui Olin. "Estás enahuizada", le dice Carlos Payán. (Poniatowska 2006: 61)

La locura poética es la que está inspirada por las musas, pero, en el caso de Nahui, la musa es ella. Posó para los fotógrafos Edward Weston ${ }^{8}$ y Antonio Garduño, quien en 1927 realizó una Exposición de Desnudos con las fotografías que le tomó en la azotea de su vivienda. Diego Rivera la retrató como la musa de la poesía erótica, Erato, en su mural La creación (1922), en la Escuela Nacional Preparatoria; la puso con uno de sus ojos enormes y con tupidas pestañas bajo un sombrero de fieltro en el fresco Día de muertos (1923), en la Secretaría de Educación Pública; y la volvió a representar con un collar de

\footnotetext{
${ }^{7}$ En este sentido, nos recuerda a otra gran escritora mexicana, Sor Juana Inés de la Cruz, que, más de tres siglos antes, en Primero sueño (1692), manifestó las mismas inquietudes.

${ }^{8}$ Edward Weston, que ya había fotografiado a Tina Modotti, afirmó, acerca de los retratos que le realizó a Nahui Olin entre 1923 y 1926, que eran los mejores que había hecho en México (The Metropolitan Museum of Art, web).
} 
perlas en medio de unos personajes de la burguesía porfiriana en Historia del teatro en México (1953), en el Teatro de los Insurgentes. El Dr. Atl, alias del vulcanólogo Gerardo Murillo, no solo la amó, sino que la retrató en una serie de pinturas que celebran el ardor de sus ojos. Y también Gabriel Fernández Ledesma, Roberto Montenegro, Ignacio Rosas, Antonio Ruiz “el Corzo”, se desempeñaron en ella.

La locura amorosa es propia de quien aspira al recuerdo de la belleza ideal y del ser auténtico y al amor libre de prejuicios. En este sentido, cabe señalar que Nahui, pese a encontrarse en un país con tantos tapujos como México, se asumió sexualmente y todo lo remitió a su cuerpo, del que admiraba las nalgas y la boquita de corazón, y a sus ardores, convirtiéndose en una maestra de la insinuación. Inicialmente contrajo nupcias con el cadete y aprendiz diplomático Manuel Rodríguez Lozano ${ }^{9}$, pero el matrimonio fue un fracaso por la definida actitud homosexual de él y porque Nahui decidió ir al encuentro del amor y del arte con el Dr. Atl, tras el regreso del matrimonio a México. El pintor la bautizó con el nombre con el que se la conoce, Nahui Olin, que alude a una fecha mágica en el calendario náhuatl: el cuarto movimiento del Sol. Junto con el Dr. Atl, vive su periodo más fecundo: en el convento de La Merced pintan, escriben, fotografían, crean, bailan, conviven con la comunidad artística y asisten a las reuniones de intelectuales ${ }^{10}$. Nahui recibía a los amigos desnuda, con una bandeja bajo sus senos y servía así sus copas de elíxires fecundantes. Lola Álvarez Bravo afirma que "Nahui siempre decía que tenía sus bebedizos para tener a todos los hombres embrujados y a todo el mundo a sus pies y que sus menjurjes y sus hierbas eran infalibles" (Poniatowska 2006: 76). La tormentosa relación se interrumpe en 1925. En 1933 se enamora del capitán Eugenio Agacino, quien inspira muchísimas obras de estilo naif de la artista, pero que muere tempranamente tras un año a causa de unos mariscos en mal estado.

A partir de su muerte, Nahui entra en una progresiva etapa de aislamiento ${ }^{11} \mathrm{y}$, aunque participa en varias exposiciones, su actividad se vuelve más esporádica. Su

\footnotetext{
${ }^{9}$ Es singular la manera en la que Nahui escogió a su esposo: lo vio desfilar y le pidió a su papá que se lo regalara (Poniatowska 2006: 65).

${ }^{10}$ El espíritu libre de Nahui quedó registrado en las cartas que le escribió al Dr. Atl y que este recogió en el libro Gentes profanas en el convento (1950).

${ }^{11}$ El sentimiento de soledad se acrecentó conforme fueron muriendo todos sus amigos: Tina Modotti en1942, José Clemente Orozco en 1949, Isabel Villaseñor en 1953, Frida Kahlo en 1954, María Izquierdo
} 
posición irreverente provocó que su producción literaria y artística fuera marginada y ella estigmatizada por las buenas conciencias. Como señala Rosas Lopátegui, "A partir de entonces, los actos de Nahui se encasillan en 'la locura'. Su libertad resulta incómoda. Su sinceridad hiere. Provoca un colapso de valores. Su sexualidad se enfrenta a la hipocresía. 'Está loca', dicen, es más fácil ver así a la mujer que decide su propia vida” (2010: 88). A Nahui, así como a Platón, lo que le interesaba era lo que el alma consigue y no consigue decir, y donde el decir no es suficiente, se abre la oscuridad del presagio y del enigma. La sexualidad pertenece al enigma y el enigma a la locura.

\section{2. Óptica cerebral: varia lucidez}

Nahui Olin publicó en total, a lo largo de su vida, cuatro libros: Óptica cerebral. Poemas dinámicos (1922), Câlinement je suis dedans (1923), A dix ans sur mon pupitre (1924) y Energía cósmica (1937), pero en esta ocasión y en defensa de su locura, hemos decidido ocuparnos de la primera, ya que no solo constituye, a nuestro parecer, una evolución adulta de la obra que compuso a los diez años, A dix ans sur mon pupitre ${ }^{12}$, sino que en ella la autora muestra una mirada sumamente lúcida de sí misma, de la mujer y de la humanidad. Nahui Olin, con esta antología de poemas y textos de prosa poética, es capaz de transformar, tal y como se comenta en el siguiente fragmento que apareció en ocasión de la publicación de la obra, la óptica cerebral en una pictórica cerebración:

Ofrecemos a nuestros lectores las primicias de un libro extraño y bello -un libro rutilante, pasional, escrito con violencia- en el que las cosas de la vida están vistas cósmicamente, un libro que desde su título, Óptica cerebral, es sugestivo, acusa la característica esencial de la obra -pictórica cerebración. Las apocalípticas visiones. Producto de una sensibilidad exquisita. Nace a la vida del arte con una obra muy personal. (Sin autor 1922: 26)

en 1955, Diego Rivera en 1957, el Dr. Atl en 1964, David Alfaro Siqueiros en 1974 y Rosario Cabrera en 1975.

12 Véase el artículo de nuestra autoría Luque 2011: 569-575. 
Nahui Olin, en esta obra, se coloca a sí misma en una posición intermedia entre el alma y el cuerpo. Según una óptica estructuralista, la cultura es como una gran estructura morfosintáctica, por lo que podemos considerar el cuerpo, bajo todos los sentidos, un signo tanto lingüístico como antropológico. En un conocido pasaje platónico del Crátilo, de hecho, se atribuye precisamente esta índole significativa al cuerpo, si bien la traducción más inmediata de la palabra (soma) con que se le define, ha llevado a la idea de que el cuerpo es prisión y tumba (sema) del alma (Platón 2000: 129). Como podemos observar en los siguientes versos, Nahui considera la materia del cuerpo, en todas sus declinaciones culturales (escultura, pintura y música) como una verdadera prisión del espíritu:

Encontrando garabatos mezquinos las artes como modo de expresión que son partos del espíritu encerrando su dolor de inexpresión en contorsionados monos que llaman esculturas, en colores que son el exterior de las cosas, sin ser ellas, sin ser la expansibilidad del espíritu que busca la expresión de esos colores, que llaman cuadros, de esos sonidos que llaman música y que son rugidos de fiera domesticada en la jaula de la materia que encierra la expansibilidad del espíritu. (Expansibilidad, $66)^{13}$

Según Michel Foucault, además, el cuerpo ha ido constituyéndose cada vez más, a lo largo de los siglos, como un nudo de relaciones de poder y de saberes paradójicos entre la inflación discursiva y la esencia de la sustancia, tanto que un cuerpo ya no es sólo un cuerpo, sino una multiplicidad de estratos, prácticas y discursividades corpóreas (Foucault 2001: 150). Nahui, de hecho, considera el cuerpo no solo la tumba del alma, sino y sobre todo, de la mujer, como podemos apreciar a continuación, en donde el cuerpo llega a transformarse en una cárcel, una mortaja de nieve o un cáncer:

\footnotetext{
${ }^{13}$ Las referencias a los poemas de Nahui están sacadas de la antología Nahui Olin. Sin principio ni fin. Vida, obra y varia invención de Patricia Rosas Lopátegui, por lo que en cada caso, citaremos, entre paréntesis, el título del poema y la página correspondiente.
} 
El crimen macho de las generaciones es engendrar el espíritu y la carne, y dentro de la carne el espíritu, y de la carne y el espíritu a la humanidad, que es la vergüenza de una impotencia, en su forma más humillante. [...] El crimen de la ola roja de las generaciones es la rebeldía del espíritu encarcelado en la impotencia de la materia. (Las generaciones en bestiales crímenes, 61 )

Bajo la mortaja de leyes humanas, duerme la masa mundial de mujeres, en silencio eterno, en inercia de muerte, y bajo la mortaja de nieve [...] pondrán en actividad su alma encerrada, en nieves perpetuas, en leyes humanas de feroz tiranía. (Bajo la mortaja de nieve duerme la Iztatzihuatl en su inercia de muerte, 63-64)

El cáncer de nuestra carne oprime nuestro espíritu sin restarle fuerza, es el cáncer famoso con que nacemos - estigma de mujer- ese microbio que nos roba vida proviene de leyes prostituidas de poderes legislativos, de poderes religiosos, de poderes paternos. (El cáncer que nos roba vida, 70 )

Como afirma Nahui en toda su producción, cuerpo y alma son entidades incompatibles, y es que en la base de dicha inconmensurabilidad subyace un oxímoron que constituye el fulcro de toda literatura epistemológica, es decir, entre el finito y el infinito. En sus poemas, el espíritu es un infinito que determina el centro de un sistema solar que se alimenta gracias a la fuerza cerebral:

No hay nada más interesante que el mundo que llevamos dentro -no hay nada más ilimitado que nuestro espíritu, y no debemos buscar ninguna otra fuerza o potencia para vivir o para producir: hay que fecundar en sus propias entrañas y dar a luz. (Supremo egoísmo, 61)

Es imposible traducir en términos, en palabras, los fenómenos maravillosos de nuestro espíritu, porque son concepciones enormes que sólo tienen vida en nuestro mismo infinito $-\mathrm{y}$ son concepciones infinitas concebidas únicamente para el infinito de nuestro espíritu. (Las ondas etéreas, 66)

El infinito que es la evolución asombrosa e imprecisable del espíritu, es un misterio de fuerza creadora [...] y cada espíritu es un sistema solar mayor o menor, que vive en el único infinito: su evolución continua y creadora, cada vez multiplicada en fuerza, en comprensión y en óptica cerebral. (El misterio de lo infinito en la evolución del espíritu, 67)

Dado que el cuerpo no puede contener el alma, la única manera para aprehenderla es comprenderla: "Y es indiscreción encantadora la comprensión que nos revela todo, que 
no permite dueño de cosa alguna porque todo es únicamente del que lo comprenda y nuestro mismo espíritu poseerá y será poseído de lo que comprende y de los que lo comprendan, y es la posesión derecho único de la comprensión de todo" (Posesión, derecho único de la comprensión de todo, 69). Como podemos observar, la posesión se transforma en una correspondencia biunívoca.

En las Láminas órficas, procedentes de tumbas de Grecia, se dice del iniciado que se muere de sed, que solo el agua fría que sale de los pantanos de la memoria pueden aliviársela. Es así como la memoria devuelve el alma a su naturaleza divina de la que el cuerpo la tenía separada (Galimberti 2007: 27). Y si la memoria, como principio primero del conocimiento, está a la base de la cultura, asistiremos al espectáculo de un alma, la de Nahui, que se muere de la sed de saber y de crear:

Mi espíritu y mi cuerpo tienen siempre loca sed / de esos mundos nuevos / que voy creando sin cesar, / y de las cosas / y de los elementos, / y de los seres, / que tienen siempre nuevas fases / bajo la influencia / de mi espíritu y mi cuerpo que tienen siempre loca / sed; inagotable sed, de inquietud creadora, / que juega con los mundos nuevos / que voy creando sin cesar / y con las cosas que son una, y que son mil. // [...] Y de esa sed admirable nace el poder creador - / y es fuego que no resiste mi cuerpo, que en continua renovación de juventud de carne y de espíritu, es único y es mil, pues es insaciable sed. // Y mi espíritu y mi cuerpo tienen siempre loca sed... (Insaciable sed, 56-57)

Si la vista es el órgano generalmente asociado al conocimiento, la "loca sed" que siente Nahui pasa también por los ojos, que para ella son "el elemento máximo, el sol de todos los sistemas solares" (Ojo, elemento humano, 65). Los ojos de Nahui ven y son vistos continuamente, como los de una pintora y los de un retrato, pero si cuando realiza la acción alivia su sed, cuando la recibe es víctima de la corporeidad, pues no la miran, solo la ven:

El verde de oblicuos agujeros, que de un rostro es lo que todos miran $-\mathrm{y}$ los que los miran no saben por qué se extrañan y miran dentro con el solo deseo de mirar, y sólo ven, y sólo saben, y sólo creen que son Verdes Agujeros Oblicuos que se 
ven sin mirar el rostro y que recuerdan piedras verdes [...] y sólo miran su belleza, su apariencia, y en su intenso color verde de enigmática fuerza, no penetran la potencia de expresión, la vibratoria inquietud, la constante rebeldía de un espíritu, de un cerebro en acción dotado de millares de fibras microscópicas, sensibles al contacto de todo átomo viviente, en toda su materia, en toda su esencia, tal cual es él mismo en su sustancia y, sobre todo, y con mayor interés a través de su interpretación cerebral, viviendo en segundos, eternidades, [...] el espíritu de un ser; encerrado en sus complejidades en densidades de verdes de oblicuos agujeros. (El verde de oblicuos agujeros, 59-60)

La vista solo es posible, además, gracias a la luz, que, en base a la alegoría platónica de la caverna, se asocia generalmente al conocimiento. En Nahui, la luz que emana su espíritu se convierte en 'luz-idez' mental ${ }^{14}$ : “[...] y es esa luz de amor cerebral que envuelve todo en belleza, de esa luz producida por el fuego del motor de dinámica inextinguible que parece en su monumental fuerza encarnar el humano espíritu" ( $\mathrm{La}$ dinámica inextinguible del motor de fuego que produce luz-el sol, 65).

Los valores del cuerpo son impedimentos de los que hay que liberarse porque la esencia del hombre se realiza verdaderamente cuando el cuerpo duerme (gracias al onirismo) o está por morir. Gracias al cerebro, la materia se consume ("[...] la fuerza asombrosa del dinamismo cerebral que consume la materia y obtiene mayor desarrollo en lo llamado inteligencia o más bien fuerza equilibrada maravillosamente", Amargura, 58) y la carne se electriza (“[...] descarga eléctrica de nuestro cerebro que como rayo, fulmina, electriza la misma carne para que sufra la acción de la emoción cerebral que es la posesión de felicidad indecible porque entra en lo ilimitado, en lo eterno que es el propio espíritu", Posesión, derecho único de la comprensión de todo, 69).

Podemos, por consiguiente, injertar la figura de Nahui en la larga tradición occidental que, desde Pablo de Tarso hasta Martín Heidegger, cuenta la historia de un espíritu que se alimenta y vive de la muerte de todo aquello que es corpóreo, natural, empírico, transeúnte, por lo que la condición de su vida es que cada uno de nosotros mire seriamente a la cara a la muerte (Galimberti 2006: 195). Solamente en este "ser para la

\footnotetext{
${ }^{14}$ No es una casualidad si la palabra "lucidez", del latín lucidus, significa 'cualidad de lúcido', es decir, ‘claro en el razonamiento' (DRAE, 2014: web).
} 
muerte", pues, se halla la realización del espíritu y, al final de la obra, Nahui llega a escribir su lápida: "Independiente fui, para no permitir pudrirme sin renovarme; hoy, independiente, pudriéndome me renuevo para vivir" (Sobre mi lápida, 72) ${ }^{15}$.

\section{Conclusiones}

Cuando Nahui murió en 1978 por una insuficiencia respiratoria, no hubo una sola esquela ni un obituario, nadie la recordó. Ya en los setenta Nahui era conocida como "la Polveada", "la Loca", "el Fantasma del Correo" porque transitaba por Tacuba y San Juan de Letrán o "la Dama de los Gatos", porque solía darles de comer a los gatos en la Alameda. También la llamaban "la Perra", "la Mano Larga" y "la Violadora", porque siempre fue, según los decires, ninfomaníaca y todavía a los ochenta y cinco años, cuando lograba subirse a un autobús o a un tranvía, les metía mano a los jóvenes pasajeros (Poniatowska 2006: 88). Nadie sospechaba que detrás de esa mujer, que pasaba sus días sentada en la Alameda, con la cara pintada a rayones y las medias caídas, vendiendo sus fotografías de desnudos de cuando era joven ${ }^{16}$, se escondía una leyenda.

Solo algunos lograron verla verdaderamente, como el poeta Homero Aradijis que, cuando la conoció en la Alameda, se dijo: "Este es un personaje literario, un personaje poético. Ya desde la actividad que estaba haciendo en la Alameda, no era una loca común que me inspiraba miedo: era una loca poética. [...] Nahui es el tipo de personaje que la sociedad destruye porque es de una inocencia totalmente desinhibida, sin compromisos, sincera" (Poniatowska 2006: 82-83). O como Tomás Zurián Ugarte, quien, a partir de 1993, cuando organizó la exposición Nahui Olin, una mujer de los tiempos modernos, empezó, gracias a su labor, a rescatarla del olvido:

\footnotetext{
15 Junto a la imagen de putrefacción del cuerpo, se da también la de la marchitación: "El inmenso dolor que reside en el corazón, marchita el cuerpo sin ablandar el espíritu en su intenso deseo" (Dolor que marchita el cuerpo, 71).

${ }^{16}$ La novela Nahui (2005) de Pino Cacucci empieza precisamente con la escena de ella que vende sus fotos fuera del Palacio de Bellas Artes.
} 


\begin{abstract}
Abriste el camino a mujeres como Frida Kahlo, Isabel Villaseñor, María Izquierdo, Benita Galeana, Aurora Reyes, María Asúnsolo, Magda Donato y tantas otras que caminaron con dignidad y talento por los campos que tú roturaste, a costa de la maldición que sobre ti cayó y que despiadada te persiguió aún más allá de la muerte, propiciando un cruel olvido.
\end{abstract}

Pero tu paso seguro, pleno de convicciones, no permitió que te dieran alcance la ignominia, el desprecio y la incomprensión, y saltaste a otra dimensión donde creaste la cultura del aislamiento y del silencio, la introspección, el diálogo contigo misma; entraste en una seductora intimidad con tu desbordante mundo interior. (Zurián 1993: 48)

El enajenado no es el que vive fuera del mundo, sino aquel que en la enajenación ha encontrado la única manera posible de estar en el mundo (Galimberti 2006: 75). Nahui no solo estuvo fuera del mundo racional, sino que ella misma, gracias a su mirada, fue el centro de un mundo interior mucho más lúcido, al que los que no saben mirar, sino solo ver, no tienen acceso.

\title{
4. Referencias bibliográficas
}

Abbagnano, Nicola. $2011^{7}$. Dizionario di filosofia. Torino: UTET.

Cacucci, Pino. 2005. Nahui. Bologna: Feltrinelli.

Foucault, Michel. 2001. "Potere e corpo". Il discorso, la storia, la verità. Interventi 19691984. Ed. Mauro Bertani. Torino: Einaudi. 149-155.

Galimberti, Umberto. 2006. Parole nomadi. Milano: Feltrinelli. 2007. Il gioco delle opinioni. Milano: Feltrinelli.

Luque, Rocío. 2011. "Entre cuerpo y alma fluyen las palabras: A los diez años, en mi pupitre de Nahui Olin". Nahui Olin. Sin principio ni fin. Vida, obra y varia invención. Ed. Patricia Rosas Lopátegui. Nuevo León: Universidad Autónoma de Nuevo León. 569-575.

Platón. 2000. Crátilo. Milano: Rizzoli. 
Poniatowska, Elena. 2006 . "Nahui Olin: la que hizo olas". Las siete cabritas. México: Era.

RAE, Diccionario de la Real Academia Española. www.rae.es. [4 dic. 2015].

Rosas Lopátegui, Patricia. 2010. Feminine Transgression. Transgresión Femenina. California: Berkeley Press.

. 2010. "Nahui Olin”. Óyeme con los ojos. De Sor Juana al siglo XXI. 21 Escritoras mexicanas revolucionarias. Ed. Patricia Rosas Lopátegui. Nuevo León: Universidad Autónoma de Nuevo León, vol. 1. 84-111.

(ed.). 2011. Nahui Olin. Sin principio ni fin. Vida, obra y varia invención. Nuevo León: Universidad Autónoma de Nuevo León.

Sin autor. 1922. "Óptica cerebral (Poemas dinámicos) de Nahui Olin (Carmen Mondragón)". Azulejos: 26-27.

The Metropolitan Museum of Art. http://metmuseum.org/collection/the-collectiononline/search/283281. [4 dic. 2015].

Zurián, Tomás. 1993. “Evocación”. Memoranda 23: 48. 